\title{
Atributos de satisfação e lealdade em serviços logísticos
}

\section{Satisfaction and loyalty attributes in logistics services}

\author{
Gérson Tontini' ${ }^{1}$ \\ Ricardo Zanchett ${ }^{2}$
}

\begin{abstract}
Resumo: O objetivo deste trabalho foi averiguar quais as principais dimensões da qualidade de serviços logísticos e mostrar como uma empresa pode utilizar a avaliação da satisfação de seus clientes com os diversos atributos do serviço, para direcionar esforços de melhoria e aumentar a lealdade de seus clientes, utilizando uma combinação da análise de importância e desempenho e do modelo Kano de qualidade. O estudo proposto caracteriza-se como uma pesquisa descritiva quantitativa. Foram pesquisados 177 clientes usuários dos serviços de uma empresa logística por meio de um questionário com 22 atributos. Os resultados demonstram que, para evitar erros de avaliação, os esforços de melhoria devem levar em consideração a relação não linear entre o desempenho dos atributos do serviço e a satisfação dos clientes. O estudo mostra que a qualidade do serviço logístico é avaliada pelos clientes em cinco dimensões (confiabilidade, responsividade, flexibilidade, segurança e empatia) e que a lealdade é mais afetada pelos atributos classificados como "chave" pelo modelo Kano de Qualidade que pelos atributos classificados como "básicos" para o serviço.
\end{abstract}

Palavras-chave: Qualidade em serviços. Serviços logísticos. Serviço. Modelo Kano. Análise de importância $\times$ desempenho.

\begin{abstract}
The objectives of this work were to study the dimensions of the perceived service quality of logistics services and to show how a company can use customers' satisfaction surveys to improve its quality and clients' loyalty. One hundred and seventy seven clients of a Logistic Company were interviewed using a 22- attribute questionnaire. The results show that in order to avoid decision errors it is important to take into consideration the non- linear effect of attributes' performance on customer satisfaction. This study also shows that logistic service quality has 5 dimensions (reliability, responsiveness, tangibles, assurance, and empathy) and that customer loyalty is more affected by the attributes classified as "key" attributes, according to the Kano Model, than those that are known as "basic" attributes.
\end{abstract}

Keywords: Service quality. Logistic services. Service. Kano Model. Importance $\times$ performance analysis.

\section{Introdução}

Atualmente, os serviços logísticos enfrentam grande competição, sendo que os clientes podem optar por uma ou outra empresa disponível no mercado para suprir suas necessidades. Para Kotler (2000), se estiverem apenas satisfeitos, os clientes podem mudar de fornecedor quando descobrirem uma oferta melhor. Assim, é necessário a qualquer empresa oferecer bens e serviços que deixem os clientes mais que satisfeitos. Nesta mesma linha, Anderson e Mittal (2000) afirmam que clientes satisfeitos tendem a repetir o consumo e a divulgar a organização a outros potenciais clientes, o que leva a um aumento no volume de negócios e, consequentemente, a um maior lucro operacional da organização. Porém, clientes insatisfeitos substituem determinado produto ou fornecedor por outra opção que, no seu julgamento, traga-lhes maior satisfação, e, ainda, divulgam suas experiências negativas, resultando no afastamento de outros potenciais consumidores. Os estudos de Anderson e Mittal (2000) confirmam este pensamento. Tendo como base o barômetro de satisfação do consumidor sueco, estes autores verificaram que um acréscimo de $1 \%$ em média no índice de satisfação resulta em um acréscimo de 2,37\% no incremento sobre os investimentos. No entanto, um decréscimo de $1 \%$ no índice de satisfação resulta em redução de 5,08\% no retorno sobre o investimento.

\footnotetext{
${ }^{1}$ Programa de Mestrado em Administração, Universidade Regional de Blumenau - FURB, Rua Antônio da Veiga, 140, Victor Konder, CEP 89012-900, Blumenau - SC, Brasil, E-mail: tontini@ furb.br

${ }^{2}$ Universidade do Oeste de Santa Catarina, São Miguel do Oeste, Rua Iapoc, 211, Centro, CEP 89900-000, São Miguel D’Oeste - SC, Brasil, E-mail: ricardo.zanchett@unoesc.edu.br
} 
Evidencia-se assim que uma queda na satisfação dos clientes produz um efeito devastador sobre os clientes potenciais, o que não acontece com tanta intensidade quando a satisfação é aumentada.

Assim, identificar o que pode influenciar a satisfação dos clientes é vital para a competitividade e lucratividade das organizações. Com o objetivo de atingir tal propósito, torna-se crucial que a empresa identifique quais atributos influenciam positivamente na satisfação e na lealdade dos clientes, os chamados atributos ganhadores de pedidos. Não menos importante é a identificação dos atributos qualificadores do serviço, pois estes afastam o cliente da empresa em futuros negócios caso não atinjam um nível mínimo de desempenho, consequentemente afetando sua lucratividade. Deste modo, a mensuração das expectativas dos clientes vem se tornando uma das principais ferramentas para a tomada de decisão nas mais diferentes organizações.

O cliente, por sua vez, vem aumentando as suas exigências a cada dia, pois o seu grau de conhecimento e de percepção das características de qualidade dos produtos e serviços também está crescendo. A satisfação do cliente é uma função do desempenho dos vários atributos do serviço e uma consequência do atendimento de suas necessidades explícitas e implícitas (TONTINI; SILVEIRA, 2007). Neste sentido, a satisfação do consumidor tem relação forte com a qualidade dos serviços ofertados pela organização, sendo uma chave para para a sustentabilidade da vantagem competitiva.

Mas como se define qualidade em serviços? Para Gitlow (1993, p. 7), a

[...] qualidade é um julgamento feito pelos clientes ou usuários de um produto ou serviço; é o grau em que os clientes ou usuários sentem que o produto ou serviço excede suas necessidades e expectativas.

sendo assim, podemos dizer que a qualidade está diretamente ligada ao complexo julgamento do consumidor.

Grönroos (1995, p. 89) afirma que a qualidade dos serviços é "[...] aquilo que os clientes percebem." Assim sendo, a qualidade de um serviço necessita ser percebida pelo cliente que, com base nas suas expectativas, assume o papel de qualificador deste serviço. Já para Slack et al. (2000, p. 552), a "[...] qualidade é a consistente conformidade com as expectativas dos consumidores.".

Zeithaml e Bitner (2003) sugerem que os clientes não percebem a qualidade como um conceito unidimensional, ou seja, as avaliações dos clientes acerca da qualidade incluem percepções de múltiplos fatores, ou dimensões, que agrupam os diferentes atributos do serviço. Gerir de forma adequada o desempenho dos atributos chave tende a aumentar a satisfação dos clientes. Assim, é relevante que uma organização identifique os diferentes atributos e dimensões da qualidade de seus serviços e gerencie o desempenho destes atributos continuamente. Isso porque todas as dimensões que envolvem a prestação de serviços têm impacto direto na avaliação da qualidade do serviço pelo consumidor e decisões que envolvam alterações do serviço, sejam elas para melhorar o serviço ou para reduzir custos, devem considerar os impactos na qualidade percebida pelo consumidor.

A terceirização das atividades de logística por parte das indústrias e empresas comerciais de grande porte obriga as empresas de transporte rodoviário de cargas a se posicionarem no mercado como operadores logísticos, ampliando o leque e a complexidade de seus serviços. Os estudos existentes na literatura sobre a qualidade dos serviços, a satisfação e a lealdade dos clientes de serviços logísticos assumem que a relação entre esses constructos é linear. Porém, Huiskonen e Pirtillä (1998) e Tontini e Silveira (2007) sugerem que a utilização de métodos lineares para identificar oportunidades de melhoria pode levar a decisões equivocadas.

O objetivo deste trabalho é averiguar quais as principais dimensões da qualidade de serviços logísticos e mostrar como uma empresa pode utilizar uma combinação de métodos lineares e não lineares na avaliação da satisfação de seus clientes com os diversos aspectos do serviço para direcionar esforços de melhoria e melhorar a satisfação e lealdade dos clientes. Assim sendo, este trabalho se justifica, visto que busca identificar nos serviços logísticos os atributos que influenciam na satisfação e na lealdade dos clientes, mostrando como superar os possíveis erros que os métodos lineares podem ocasionar na identificação de oportunidades de melhoria.

\section{Dimensões da qualidade dos serviços e sua importância para o consumidor}

Parasuraman, Zeithaml e Berry (1985) realizaram uma pesquisa qualitativa com 12 grupos de foco com clientes de quatro categorias de serviços (bancos, seguradoras, cartão de crédito e consertos) com o objetivo de identificar os atributos influenciadores da avaliação da qualidade por parte dos clientes, tendo-os agrupados em 10 dimensões (PARASURAMAN; ZEITHAML; BERRY, 1985). Depois de diversos estudos realizados pelos autores, observou-se que um grupo de atributos repetia-se com frequência e sua concentração era em um menor grupo de dimensões, que seriam (PARASURAMAN; ZEITHAML; BERRY, 1988): 
- Confiabilidade - A habilidade para executar o serviço conforme prometido de modo seguro e preciso.

- Responsividade - A vontade de ajudar os clientes e de prestar serviços sem demora.

- Segurança-Conhecimentos dos funcionários, aliado à simpatia e sua habilidade para inspirar credibilidade e confiança. É a confiança que o cliente tem em fazer negócios com a empresa.

- Empatia - Cuidado, atenção individualizada dedicada aos clientes. Entendimento das necessidades dos clientes.

- Tangíveis - Aparência das instalações físicas, equipamento, pessoal e material impresso.

Embora Parasuraman, Zeithaml e Berry (1988) tenham encontrado cinco dimensões para a qualidade em serviços, diversos autores coincidem em afirmar que o cliente avalia a qualidade em diferentes dimensões, porém divergem no número e sobre quais sejam essas dimensões, dependendo do tipo de serviço analisado (LADHARI, 2009). Landrum e Prybutok (2004), estudando as dimensões da qualidade de serviços de bibliotecas, encontraram apenas dimensões, tangíveis, confiabilidade e uma dimensão que integrou responsividade, empatia e segurança. Gefen (2002) aplicou um modelo adaptado do SERVQUAL para serviços on-line e também relatou três dimensões: i) tangíveis; ii) dimensão combinada de responsividade, confiabilidade e segurança; e iii) empatia. Já Ladhari (2010) encontrou seis dimensões para a qualidade de serviços on-line: confiabilidade, responsividade, facilidade de uso, privacidade/segurança, web design, benefício ou qualidade da informação. Chowdhary e Prakash (2007) também relataram que o número de dimensões da qualidade do serviço variava de uma a oito dimensões em estudos prévios. Estes estudos mostram que tanto as dimensões da qualidade em serviços, quanto os instrumentos para medi-las depende do contexto específico de cada indústria.

Outro ponto a ser observado diz respeito à importância das diferentes dimensões para os clientes. Neste contexto, Berry e Parasuraman (1992) salientam que a confiabilidade do serviço é a dimensão mais importante. Pesquisas realizadas pelos autores em mais de 1900 empresas, em que se solicitou aos entrevistados que distribuíssem 100 pontos entre as cinco dimensões, mostraram a seguinte distribuição: confiabilidade (32), responsividade (22), segurança (19), empatia (16) e tangíveis (11). Segundo os autores, a confiabilidade é essencial à qualidade dos serviços, sendo um dos primeiros critérios a ser avaliado pelos clientes. Porém, esta importância pode variar entre os diferentes tipos de serviços. Esta relação de importância é suportada pelos estudos de Landrum e Prybutok (2004) e Ling e Chong (2005).
Assim, a identificação das dimensões relevantes para a qualidade de um serviço, e dos atributos que formam essas dimensões, torna-se relevante para uma empresa melhor gerenciar a satisfação de seus clientes.

\section{Dimensões da qualidade em serviços logísticos}

Como já exposto, qualquer serviço é mais bem entendido e mensurado quando desagregado em atributos específicos. Com o objetivo de melhor entender quais elementos compõem um serviço logístico de qualidade, muitas pesquisas foram direcionadas para esta área, sendo que os resultados de algumas delas serão apresentados a seguir.

Em uma pesquisa com empresas de transporte marítimo na China, Lu (2000) identificou uma série de atributos de serviços que, após uma análise fatorial, foram agrupados e chamados de fatores críticos de sucesso. Destacou-se como fator crítico de sucesso a confiabilidade, que agrupava os atributos: pronta resposta a reclamações, informações precisas e baixa variabilidade do tempo de entrega. Assim este autor corrobora o proposto por Berry e Parasuraman (1992), de que a confiabilidade é a dimensão mais importante. Ainda segundo Lu (2000), algumas dimensões da qualidade em serviços logístico, identificadas como críticas para um grupo de empresas, podem não ser as mesmas para outro grupo. Segundo o autor, isto se justifica principalmente por conta de fatores associados ao tamanho da empresa, área de atuação, localização geográfica, fatores socioeconômicos, entre outros.

Em seu estudo, Ballou (2001) afirma que, para conseguir confiabilidade nos serviços logísticos, deve-se estabelecer patamares de desempenho que resultem no nível de serviço esperado pelo cliente. Reforça o autor que, antes de estabelecer estes patamares, é fundamental identificar os elementos-chave que determinam as reais necessidades de serviços dos clientes e de que forma estas podem ser medidas.

Martínez Caro e Martínez Garcia (2007) encontraram quatro grandes dimensões para a qualidade do serviço logístico: interação pessoal (conduta das pessoas, conhecimento e resolução de problemas), design (gama de serviços oferecidos, horas de operação convenientes), ambiente físico (tangíveis e informações sobre pedido), resultado (pontualidade e valor percebido).

Diversos trabalhos apresentados na literatura científica argumentam e pesquisam sobre as diferentes dimensões da qualidade de serviços logísticos. Uma análise desses trabalhos sugere a existência de 13 dimensões:

- Confiabilidade do prazo entrega - diz respeito à capacidade da empresa prestadora de serviço de entregar o pedido no prazo acordado e de forma constante. 
- Agilidade na entrega - Diz respeito ao tempo de ciclo do pedido, a rapidez com que o pedido é entregue. Enquanto que a dimensão da confiabilidade do prazo de entrega trabalha com a variação no desempenho do serviço, a dimensão agilidade na entrega diz respeito ao desempenho médio, ao prazo de entrega.

- Confiabilidade da quantidade correta - diz respeito à capacidade de atender às solicitações de forma integral, sem quebra dos pedidos ou variações na quantidade.

- Confiabilidade do produto correto - diz respeito a não existência de erros nos pedidos ou substituição de produtos na entrega. No caso de empresas transportadoras, engloba a entrega do produto no local correto.

- Entrega sem danos ao produto - diz respeito ao índice de defeitos dos produtos e danos ocorridos durante o transporte.

- Flexibilidade no serviço prestado - diz respeito à capacidade da empresa prestadora do serviço em se adequar às necessidades do cliente, quanto a pedidos especiais, de urgência, capacidade de transportar cargas especiais ou perigosas, tamanho do lote de entrega e flexibilidade nos horários de coleta e entrega.

- Recuperação de falhas - diz respeito ao comportamento da empresa na ocorrência de falhas em seu serviço, tanto no que diz respeito ao tratamento das reclamações quanto à velocidade de correção dos problemas.

- Rastreabilidade - diz respeito ao fornecimento de informações ao cliente sobre a situação do pedido e ao controle das operações de entrega.

- Comunicação - diz respeito a todos os aspectos de comunicação da empresa com o cliente, incluindo aviso antecipado de atrasos, clareza nas condições do contrato de fornecimento do serviço, qualidade das informações técnicas, previsão de data de entrega, etc.

- Confiança e conhecimento da equipe de contato com o cliente - inclui o conhecimento e profissionalismo demonstrado pela equipe e a confiabilidade das informações prestadas por estes.

- Disponibilidade dos produtos e do serviço Inclui a disponibilidade em estoque dos produtos solicitados ou a disponibilidade de meios para prestação do serviço.

- Apoio pós-entrega - são todas as ações da empresa prestadora de serviço após a entrega das mercadorias na empresa. Inclui apoio na venda dos produtos entregues, serviços de intermediação com fornecedores e apoio na entrega do produto para os clientes.

- Preço - inclui política de preço e condições de venda.

O Tabela 1 mostra os autores que citaram cada uma das dimensões. As dimensões de agilidade na entrega, confiabilidade do prazo de entrega e entrega na quantidade correta foram as mais citadas pelos autores, refletindo o próprio conceito da atividade de logística que, segundo Christopher (1997), consiste na oferta consistente de utilidade no tempo e lugar, o que poderia ser simplificado, afirmando que os serviços logísticos têm como objetivo disponibilizar o produto certo na hora certa.

\section{Identificando o que melhorar em um serviço}

Métodos diversos têm sido utilizados para direcionar os esforços de melhoria em bens e serviços. Um deles é a matriz de importância e desempenho, que recomenda ações de melhoria, manutenção ou desinvestimento (MARTILLA; JAMES, 1977). Geralmente, dados provenientes de pesquisas sobre satisfação do consumidor são utilizados para construir uma matriz bidimensional, na qual a importância é mostrada pelo eixo y e o desempenho do atributo pelo eixo x. A matriz é dividida em quatro quadrantes. Um atributo que tiver alta importância e alto desempenho representa uma possível vantagem competitiva. Nesse caso, a empresa deve "manter o bom trabalho". Um atributo que tiver alta importância e baixo desempenho deverá receber atenção imediata. Para aumentar a satisfação geral, os dirigentes da empresa deveriam se concentrar em melhorá-lo. Atributos com baixa importância e baixo desempenho não necessitam de esforço adicional. Já atributos com alto desempenho, porém com baixa importância, podem significar que a empresa esteja desperdiçando recursos que poderiam ser mais bem aproveitados em outras aplicações.

Segundo Garver (2003), o desempenho pode ser obtido pela avaliação da satisfação dos clientes com os atributos individuais. A importância dos atributos pode ser obtida pela importância declarada ou pela importância derivada estatisticamente.

A importância declarada é obtida por uma nota dada pelo cliente para cada atributo, em uma escala que pode variar de "sem importância" até "extremamente importante". A importância derivada pode ser obtida pedindo-se aos clientes para avaliar sua satisfação com os diversos atributos e sua satisfação geral com o serviço. Então, vários métodos podem ser utilizados para derivar a importância dos atributos, tais como: regressão múltipla, análise de componentes principais, correlação parcial entre os atributos e a satisfação geral (GUSTAFSSON; JOHNSON, 2004). 
Tabela 1. Dimensões da qualidade em serviços logísticos segundo a literatura.

\begin{tabular}{|c|c|c|c|c|c|c|c|c|c|c|c|c|c|c|c|}
\hline & 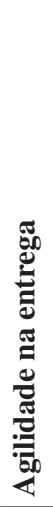 & 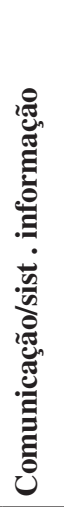 & 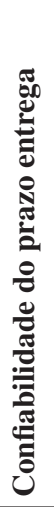 & 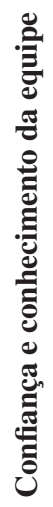 & 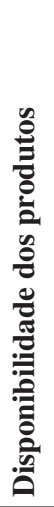 & 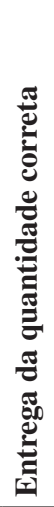 & 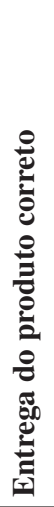 & 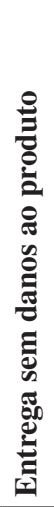 & 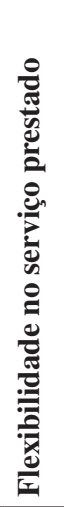 & 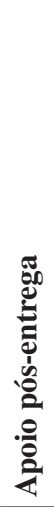 & 递 & 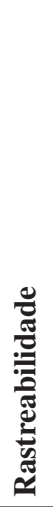 & 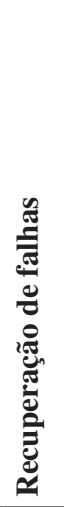 & 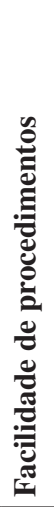 & 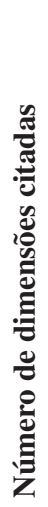 \\
\hline 1 - Ballou (1995) & $\mathrm{X}$ & $\mathrm{X}$ & $\mathrm{X}$ & - & - & $X$ & - & - & $\mathrm{X}$ & - & - & $\mathrm{X}$ & $\mathrm{X}$ & - & 7 \\
\hline $\begin{array}{l}2 \text { - Lambert e Sterling (1993 apud } \\
\text { MORAES; LACOMBE, 1999) }\end{array}$ & $X$ & $X$ & $X$ & - & $X$ & $\mathrm{X}$ & - & - & $X$ & - & - & - & - & - & 6 \\
\hline 3 - Christopher (1997) & $X$ & $X$ & $\mathrm{X}$ & - & $\mathrm{X}$ & $X$ & - & - & $X$ & - & - & $X$ & $X$ & - & 8 \\
\hline 4 - Heskett (1971) & $X$ & & & - & $X$ & $X$ & - & $X$ & $X$ & - & - & - & - & - & 5 \\
\hline $\begin{array}{l}5 \text { - Sharma, Grewal e Levy (1995 } \\
\text { apud MORAES; LACOMBE, 1999) }\end{array}$ & $\mathrm{X}$ & $X$ & $X$ & - & $\mathrm{X}$ & - & - & - & - & - & - & - & $\mathrm{X}$ & - & 5 \\
\hline 6 - Bowersox e Closs (2001) & $\mathrm{X}$ & - & $\mathrm{X}$ & - & $\mathrm{X}$ & $X$ & - & - & $\mathrm{X}$ & - & - & - & - & - & 5 \\
\hline 7 - Emerson e Grimm (1998) & $\mathrm{X}$ & $\mathrm{X}$ & $\mathrm{X}$ & $\mathrm{X}$ & $\mathrm{X}$ & $\mathrm{X}$ & $\mathrm{X}$ & $\mathrm{X}$ & - & $\mathrm{X}$ & $\mathrm{X}$ & $\mathrm{X}$ & $X$ & - & 12 \\
\hline $\begin{array}{l}8 \text { - Centro de Estudos em } \\
\text { Logística (2003) }\end{array}$ & $\mathrm{X}$ & $\mathrm{X}$ & $\mathrm{X}$ & $X$ & $\mathrm{X}$ & $\mathrm{X}$ & - & $\mathrm{X}$ & $\mathrm{X}$ & $\mathrm{X}$ & - & $\mathrm{X}$ & $\mathrm{X}$ & - & 11 \\
\hline 9 - Ellram, La Londe e Weber (1999) & $\mathrm{X}$ & $\mathrm{X}$ & $\mathrm{X}$ & - & - & $\mathrm{X}$ & - & $\mathrm{X}$ & - & - & - & $\mathrm{X}$ & $X$ & - & 7 \\
\hline 10 - Bienstock, Mentzer e Bird (1997) & $\mathrm{X}$ & - & $X$ & - & $\mathrm{X}$ & - & $\mathrm{X}$ & $\mathrm{X}$ & - & - & - & - & - & - & 5 \\
\hline 11 - Mentzer et al. (2001) & $\mathrm{X}$ & $\mathrm{X}$ & $\mathrm{X}$ & $\mathrm{X}$ & - & $\mathrm{X}$ & $\mathrm{X}$ & $\mathrm{X}$ & $\mathrm{X}$ & - & - & - & $\mathrm{X}$ & - & 9 \\
\hline 12 - Forslund (2003) & $\mathrm{X}$ & $\mathrm{X}$ & $X$ & - & $\mathrm{X}$ & $\mathrm{X}$ & - & $\mathrm{X}$ & $X$ & - & - & - & - & - & 7 \\
\hline 13 - Gustafsson (2003) & $X$ & $\mathrm{X}$ & $\mathrm{X}$ & $\mathrm{X}$ & - & $X$ & $\mathrm{X}$ & $\mathrm{X}$ & $\mathrm{X}$ & - & - & - & $X$ & - & 9 \\
\hline 14 - Souza, Moori e Marcondes (2003) & $\mathrm{X}$ & $\mathrm{X}$ & $\mathrm{X}$ & $\mathrm{X}$ & $\mathrm{X}$ & $\mathrm{X}$ & - & $\mathrm{X}$ & - & - & - & - & $\mathrm{X}$ & - & 8 \\
\hline 15 - Lambert e Harrington (1989) & $\mathrm{X}$ & $\mathrm{X}$ & $\mathrm{X}$ & - & - & $\mathrm{X}$ & - & - & - & - & - & - & $X$ & - & 5 \\
\hline $\begin{array}{l}16 \text { - Harrington, Lambert e } \\
\text { Christopher (1991) }\end{array}$ & $X$ & - & - & - & $\mathrm{X}$ & $\mathrm{X}$ & - & - & - & - & $X$ & - & - & - & 4 \\
\hline 17 - Holcomb (1994) & $\mathrm{X}$ & - & $\mathrm{X}$ & - & - & $\mathrm{X}$ & - & - & $X$ & - & - & $X$ & $X$ & - & 6 \\
\hline 18 - Bowersox e Closs (1996) & $\mathrm{X}$ & - & $\mathrm{X}$ & - & $\mathrm{X}$ & - & - & - & $X$ & - & - & - & $X$ & - & 5 \\
\hline 19 - Harding (1998) & - & - & - & - & - & $\mathrm{X}$ & - & - & - & $\mathrm{X}$ & $\mathrm{X}$ & - & - & - & 3 \\
\hline 20 - Mentzer, Flint e Kent (1999) & - & $X$ & $\mathrm{X}$ & - & - & $X$ & - & - & - & - & $X$ & - & $X$ & - & 5 \\
\hline 21 - Fleury e Silva (2000) & $X$ & $X$ & $X$ & - & $X$ & - & - & - & $X$ & $\mathrm{X}$ & - & - & $X$ & - & 7 \\
\hline 22 - Bienstock et al. (2008) & $\mathrm{X}$ & $\mathrm{X}$ & - & $\mathrm{X}$ & - & $\mathrm{X}$ & $\mathrm{X}$ & $\mathrm{X}$ & - & - & - & - & $\mathrm{X}$ & $\mathrm{X}$ & 8 \\
\hline 23 - Gonçalves Filho et al. (2007) & $X$ & - & - & $X$ & $X$ & $X$ & $\mathrm{X}$ & $\mathrm{X}$ & $\mathrm{X}$ & - & - & - & $X$ & - & 8 \\
\hline Número de Citações & 20 & 15 & 18 & 6 & 13 & 18 & 5 & 10 & 12 & 4 & 4 & 6 & 15 & 1 & - \\
\hline
\end{tabular}

Está fora do escopo deste artigo fazer uma revisão das vantagens e desvantagens de cada método. Mais informações podem ser obtidas em Garver (2003) e Tontini e Silveira (2007).

A matriz de importância e desempenho tem como pressuposto a linearidade entre o desempenho dos atributos e a satisfação, porque considera que qualquer atributo, ao ser melhorado, refletirá em aumento de satisfação. Contudo, alguns tipos de atributos não proporcionam aumento na satisfação do consumidor na mesma proporção que o aumento de desempenho, apresentando uma relação não linear entre desempenho e satisfação geral. Esta relação não linear entre a satisfação com os atributos individuais e a satisfação geral pode levar a decisões equivocadas de melhoria quando se utiliza isoladamente a matriz de importância e desempenho (HUISKONEN; PIRTTILÄ, 1998; TONTINI; SILVEIRA, 2007).

O modelo Kano de Qualidade Atrativa e Obrigatória (KANO et al., 1984; BERGER et al., 1993; MATZLER et al., 1996; NILSON-WITELL; FUNDIN, 2005) propõe que o relacionamento entre 
o desempenho com os atributos e a satisfação geral do cliente é, na verdade, não linear, classificando os atributos como básicos (ou obrigatórios), chave (ou unidimensionais), atrativos e neutros. Os atributos básicos estão relacionados com as funções essenciais do serviço. Geralmente os clientes não percebem a presença destes atributos, mas sua ausência ou baixo desempenho traz grande insatisfação. Para os atributos-chave, a satisfação varia de forma proporcional ao desempenho. Os atributos atrativos trazem alta satisfação e reconhecimento por parte dos clientes se estiverem presentes, porém não trazem insatisfação se seu desempenho for insuficiente ou se estiverem ausentes.

Ignorar a existência destes atributos, cujo desempenho influencia de forma não linear a satisfação dos clientes, pode levar a decisões equivocadas sobre o que deveria ser melhorado em um serviço. Os problemas aparecem na análise de importância e desempenho para os atributos básicos e atrativos, dependendo de três aspectos: do desempenho destes atributos em relação aos competidores, do desempenho médio dos competidores para o atributo e a da experiência anterior do cliente. A Tabela 2 resume os problemas de decisão que podem ocorrer.

Assim, deve-se analisar a necessidade de melhoria dos diferentes atributos do serviço pela matriz de importância e desempenho levando-se em consideração a classificação do atributo pelo modelo Kano. Mas como podemos determinar essa classificação dos atributos?

Métodos diferentes, levando a resultados também diferentes (WITELL; LOFGREN, 2007), têm sido usados para identificar a classificação dos atributos segundo o modelo Kano. O método original é baseado em um questionário construído com duas questões hipotéticas para cada atributo, uma de suficiência e outra de insuficiência (KANO et al., 1984; BERGER et al., 1993). Kano (2001) sugeriu a utilização de menos alternativas de resposta nas perguntas de suficiência e insuficiência. Tontini e Sant'Anna (2007) propõem o método de análise do gap de melhoria, usando a satisfação atual e as questões de suficiência e insuficiência para classificar os atributos. Esses métodos, usando questões de suficiência e insuficiência, aumentam o tamanho do questionário, podendo levar a dificuldades na pesquisa de campo.

Emery e Tian (2002) usaram um método de avaliação direta, pedindo aos clientes que classificassem diretamente os atributos segundo o modelo Kano. Este método necessita que o cliente entenda o conceito de cada classificação, o que aumenta o tempo e a complexidade da pesquisa.

Brandt (1988), Anderson e Mittal (2000), Matzler e Sauerwein, (2002) e Mittal, Ross e Baldasare (1998) classificam os atributos baseados nos coeficientes da regressão entre a satisfação com os atributos individuais e a satisfação geral, recodificando a satisfação com os atributos em variáveis dummy. Este método, chamado de Análise do Contraste da Penalidade e da Recompensa (PRC), reduz o tamanho do questionário, porém apresenta a limitação de indicar como não significativos atributos inovadores, pois o cliente não tem experiência com eles. Outra limitação diz respeito à sensibilidade do PRC ao ponto de divisão da escala para recodificação das variáveis de recompensa e de penalidade em variáveis dummy. Informações detalhadas sobre este método podem ser encontradas em Picolo e Tontini (2008).

Jacobs (1999), Martensen e Grönholdt (2001) usaram uma matriz de importâncias para classificar os atributos. O método consiste em determinar a importância derivada e a importância declarada para cada atributo. Atributos que recebem alta importância em ambos os métodos, são considerados atributoschave. Atributos que recebem baixa importância em ambos os métodos, são considerados neutros. Aqueles atributos que recebem alta importância declarada e baixa importância derivada são considerados básicos. Já aqueles que recebem baixa importância declarada e mais alta importância derivada são considerados amplificadores, ou atrativos. Este método tem a mesma limitação do método PRC para atributos inovadores, pois, neste caso, segundo Tontini e Silveira (2007), como os clientes não conhecem o benefício do atributo, as duas importâncias tendem a ser baixas, levando a se considerar o atributo como neutro. Porém, o método apresenta a vantagem de que se a organização quiser focar apenas nos atributos que são conhecidos pelos clientes, o questionário fica reduzido, pois é necessário apenas se perguntar a satisfação atual e a importância dos atributos, além da satisfação geral com o serviço.

\section{Caracterização da empresa pesquisada}

A empresa de serviços logísticos, objeto deste estudo, foi criada em $1^{\circ}$ de abril de 1976 , no extremo oeste catarinense, tendo como propósito, inicialmente, o transporte de cargas fracionadas e mudanças. A partir de 1977, a empresa inicia o transporte e distribuição de cargas para grandes indústrias. Para tornar-se competitiva na área de atuação, a empresa passou a oferecer os seguintes serviços:

a) Transportes e distribuição de cargas fracionadas em geral - atividade direcionada e adaptada à realidade da região, formada por um grande número de pequenas empresas.

b) Transportes e distribuição dirigida de cargas completas - atividade direciona à empresa de porte médio e grande. 
Tabela 2. Problemas na análise de importância e desempenho tradicional devido à relação não linear entre desempenho e satisfação.

\begin{tabular}{|c|c|c|c|c|c|c|}
\hline $\begin{array}{l}\text { Classific. } \\
\text { Kano }\end{array}$ & $\begin{array}{l}\text { Import. } \\
\text { para o } \\
\text { cliente }\end{array}$ & $\begin{array}{l}\text { Desempenho } \\
\text { competitivo }\end{array}$ & $\begin{array}{c}\text { Desempenho } \\
\text { médio do } \\
\text { mercado }\end{array}$ & $\begin{array}{c}\text { Decisão da } \\
\text { análise e imp. } \times \\
\text { desempenho }\end{array}$ & Razões para o erro & Resultado \\
\hline Básico & Alta & Igual & Suficiente & Melhorar & $\begin{array}{l}\text { Melhorar acima do } \\
\text { nível atual não levará a } \\
\text { aumento de satisfação } \\
\text { dos clientes. }\end{array}$ & $\begin{array}{l}\text { Desperdício de } \\
\text { recursos. }\end{array}$ \\
\hline Básico & Baixa & Superior & Suficiente & Abandonar & $\begin{array}{l}\text { Experiências } \\
\text { anteriores gratificantes } \\
\text { e um bom } \\
\text { desempenho médio } \\
\text { do mercado levam os } \\
\text { consumidores a não } \\
\text { reconhecerem sua } \\
\text { importância. }\end{array}$ & $\begin{array}{l}\text { Atributo } \\
\text { importante } \\
\text { deixado sem } \\
\text { atenção ou } \\
\text { abandonado, } \\
\text { podendo levar à } \\
\text { insatisfação dos } \\
\text { clientes. }\end{array}$ \\
\hline Básico & Alta & Inferior & Suficiente & Melhorar & & Decisão Correta \\
\hline Atrativo & Baixa & $\begin{array}{l}\text { Inferior ou } \\
\text { igual }\end{array}$ & Insuficiente & Abandonar & $\begin{array}{l}\text { Clientes não conhecem } \\
\text { os benefícios do } \\
\text { atributo. }\end{array}$ & $\begin{array}{l}\text { Oportunidade de } \\
\text { melhoria relevante } \\
\text { desperdiçada. }\end{array}$ \\
\hline Atrativo & Alta & $\begin{array}{l}\text { Igual ou } \\
\text { inferior }\end{array}$ & Insuficiente & Melhorar & $\begin{array}{l}\text { Experiências } \\
\text { anteriores gratificantes } \\
\text { levam os clientes a } \\
\text { dizer que o atributo é } \\
\text { importante. }\end{array}$ & $\begin{array}{l}\text { Melhoria de um } \\
\text { atributo que pode } \\
\text { ser não crítico, } \\
\text { desviando recursos } \\
\text { de outras áreas. }\end{array}$ \\
\hline Atrativo & Alta & Superior & Insuficiente & Manter & & Decisão Correta \\
\hline
\end{tabular}

Fonte: Adaptado de Huiskonen e Pirtillä (1998).

c) Transportes e distribuição especial de cargas perecíveis - atividade especializada em cargas com características especiais e que necessitam de uma estrutura diferenciada.

d) Armazém geral - estrutura que permite armazenar mercadorias, permitindo maior flexibilidade no gerenciamento das operações.

e) Operador logístico - atividade ligada à logística integrada, contemplando serviços de distribuição e infraestrutura de armazenagem, gerenciamento de estoques, equipamentos para movimentação interna, etc.

Com o objetivo de atender ao crescente interesse pela terceirização da logística integrada, foi criada a atividade de Operador Logístico, oferecendo, além da distribuição física das mercadorias aos clientes finais, toda a infraestrutura necessária para a atividade, ou seja, oferecendo serviços de armazenagem, administração de estoques, instalações, equipe treinada e equipamentos adequados às necessidades de cada empresa.

A empresa contava na época da pesquisa, em 2008, com 142 colaboradores nas 57 unidades em 17 estados.

\section{Método da pesquisa}

O estudo proposto caracterizou-se por ser uma pesquisa descritiva quantitativa. Para a realização do presente estudo, foram pesquisados os clientes usuários dos serviços logísticos da empresa pesquisada. Esta empresa é caracterizada como uma empresa de pequeno porte, tendo como principal atividade a prestação de serviços logísticos. A empresa atua nos três Estados do sul do Brasil, no entanto, sua participação é mais atuante no extremo oeste de Santa Catarina.

Os clientes pesquisados neste estudo foram escolhidos entre os que faziam parte do cadastro ativo da empresa. Neste caso, consideraram-se como clientes ativos os que utilizaram os serviços logísticos da empresa pelo menos uma vez no mês anterior à pesquisa. Desta forma, determinou-se a amostra de clientes com base no cadastro da empresa no mês de outubro de 2008. Neste mês, a empresa contava com 1.876 clientes no seu quadro de clientes, sendo que, destes, 561 clientes utilizaram os serviços da empresa no mês de outubro de 2008. Todos os clientes foram contatados, sendo que foram obtidas 183 respostas.

Apuraram-se os desvios padrão dos atributos dos 183 questionários, que representam os clientes 
pesquisados, bem como a contagem das notas atribuídas na avaliação e na importância atribuída a cada atributo pelo cliente. Com a apuração do desvio padrão, identificaram-se aqueles clientes que atribuíram a mesma avaliação e a mesma importância para todos os atributos. Estes questionários foram excluídos das análises por se entender que não representam à realidade da situação.A contagem das notas atribuídas permitiu identificar se o cliente deixou de atribuir alguma nota na avaliação ou na importância dos atributos. Quando o respondente não atribuiu avaliação à metade dos atributos ou da importância, optou-se também por excluí-lo das demais análises.Desta forma, dos 183 questionários que retornaram da pesquisa de campo, utilizaram-se 177 para as diversas análises estatísticas.

Por se tratar de uma pesquisa descritiva, o instrumento usado para a coleta de dados foi um questionário composto por perguntas fechadas. Com o objetivo de melhor organização dos dados coletados, o questionário foi dividido em três etapas. Na primeira etapa, buscou-se caracterizar a empresa cliente pesquisada. Na segunda parte do instrumento de coleta de dados, os clientes pesquisados avaliaram o serviço oferecido pela empresa de logística. Esta avaliação se deu por meio de uma nota atribuída a cada um dos atributos dos serviços logísticos, bem como para a satisfação geral e para a lealdade. Os clientes atribuíram uma nota para cada atributo e para a satisfação geral, variando de -5 (extremamente insatisfeito) a +5 (extremamente satisfeito). Para a lealdade, os clientes pesquisados responderam sobre sua intenção em continuar trabalhando com a Empresa Logística, atribuindo uma nota variando de 1 a 11.

$\mathrm{Na}$ terceira e última etapa, os respondentes atribuíram uma nota, variando de 1 (sem importância) a 7 (muito importante), para cada atributo da pesquisa. Neste caso, usaram-se os mesmos atributos da segunda etapa. A Tabela 3 apresenta os atributos pesquisados neste estudo, bem como sua correlação com as dimensões reveladas no Tabela 1.

As dimensões "disponibilidade" e "apoio pós-venda" não foram pesquisadas devido a empresa logística ser apenas uma operadora logística, não mantendo em estoque produtos que poderiam ser ordenados pelos clientes. Essas dimensões são mais adequadas quando se trata de operadores do tipo atacadistas. Já a dimensão preço não foi pesquisada por se tratar de uma dimensão adicional, não considerada como uma dimensão da qualidade e sim como uma dimensão comercial.

A classificação dos atributos segundo o modelo Kano foi realizada por meio da matriz de importâncias. A análise das ações de melhoria foi efetuada usando-se a importância derivada estatisticamente e a satisfação individual com os atributos pesquisados, em uma matriz de importância e desempenho. A importância derivada foi determinada por meio da correlação parcial entre a satisfação individual com os atributos e a satisfação geral com os serviços, controlando-se pela frequência de utilização dos serviços da empresa logística e se o cliente utiliza os serviços de outra empresa.

\section{Resultados da pesquisa}

Quanto à frequência de utilização dos serviços, constatou-se que 47 clientes (26\%) pesquisados recorrem aos serviços da empresa uma vez por semana e que 37 clientes $(20 \%)$ recorrem aos serviços da empresa mais que uma vez por semana. É valido lembrar que, ao selecionar a amostra a ser trabalhada, optou-se por trabalhar com os clientes que utilizaram os serviços da empresa nos últimos 30 dias, por entender que estes clientes teriam capacidade de melhor avaliar os serviços da empresa.

Quanto ao porte das empresas, perguntou-se o número de funcionários. Assim, 116 clientes (63\%) pesquisados possuem de 20 a 49 funcionários, 33 clientes (18\%) possuem até 19 funcionários, 25 clientes (14\%) entre 50 e 100 funcionários, e apenas 9 clientes (5\%) declararam ter mais que 100 funcionários. Com esta informação foi possível concluir que, segundo o SEBRAE-SC (2010), a maioria dos clientes pesquisados são empresas de pequeno porte.

Buscou-se também levantar o faturamento dos clientes pesquisados, tendo como base o ano de 2007. Esta informação vem complementar a questão anterior que levantou o número de funcionários dos clientes, permitindo assim retratar com mais precisão o porte dos clientes da empresa. Para alinhar as informações optou-se por adotar a mesma faixa de faturamento utilizado pelo SEBRAE. A grande maioria dos clientes pesquisados, 100 clientes (55\%), declarou ter faturamento entre $\mathrm{R} \$ 240.001,00 \mathrm{a}$ $\mathrm{R} \$ 2.400 .000,00$ por ano. Utilizando-se da mesma classificação adotada pelo SEBRAE-SC (2010), estas empresas classificam-se como Empresa de Pequeno Porte - EPP.

Dos clientes pesquisados, 152 clientes (83\%) assumiram que utilizam, além da empresa estudada, outras empresas que oferecem serviços logísticos. Apenas 31 clientes (17\%) disseram que não utilizam outra empresa para seus serviços logísticos. Este resultado confirma a grande competição existente no setor em que o cliente, caso não tenha suas expectativas atendidas, pode substituir seu fornecedor atual por outro disponível no mercado.

\section{Dimensões da qualidade do serviço logístico pesquisado}

Para averiguar se os clientes da empresa pesquisada avaliam a qualidade da empresa segundo as dimensões sugeridas na literatura, efetuou-se uma análise fatorial 
Tabela 3. Atributos dos serviços logísticos.

\begin{tabular}{|c|c|c|}
\hline Atributos & Descrição dos atributos & Dimensão \\
\hline At1 & Pontualidade na entrega (cumprir o prazo de entrega) & $\begin{array}{l}\text { Confiabilidade do } \\
\text { prazo de entrega }\end{array}$ \\
\hline At2 & Entrega do produto correto & $\begin{array}{l}\text { Entrega do produto } \\
\text { correto }\end{array}$ \\
\hline At3 & Capacidade de prestar serviço completo (entrega completa) & $\begin{array}{l}\text { Entrega da quantidade } \\
\text { correta }\end{array}$ \\
\hline At4 & Índice de defeitos nas mercadorias transportadas & $\begin{array}{l}\text { Entrega sem danos ao } \\
\text { produto }\end{array}$ \\
\hline At5 & Capacidade da empresa em prestar serviços de urgência ou especiais & Flexibilidade \\
\hline At6 & Flexibilidade de prazos de coleta e entrega & Flexibilidade \\
\hline At7 & Políticas para devolução de mercadorias enviadas erradas pelos fornecedores & Recuperação de falhas \\
\hline At8 & Frequência e periodicidade de coleta e entrega & Agilidade na entrega \\
\hline At9 & Aviso antecipado de atrasos & Comunicação \\
\hline At10 & Informações sobre Status do pedido (rastreabilidade) & Rastreabilidade \\
\hline At11 & Agilidade na entrega (tempo entre coleta e entrega) & Agilidade na entrega \\
\hline At12 & Recuperação das falhas eventualmente ocorridas no serviço. & Recuperação de falhas \\
\hline At13 & $\begin{array}{l}\text { Capacidade de entrega de produtos que exijam cuidados especiais ou } \\
\text { diferentes (flexibilidade no tipo de carga que pode transportar) }\end{array}$ & Flexibilidade \\
\hline At14 & $\begin{array}{l}\text { Cordialidade no atendimento pelo pessoal da linha de frente (motoristas, } \\
\text { escritório, etc.) }\end{array}$ & $\begin{array}{l}\text { Confiabilidade do } \\
\text { prazo de entrega }\end{array}$ \\
\hline At15 & Rapidez no atendimento quando você entra em contato com a empresa & Agilidade na entrega \\
\hline At16 & Nível de conhecimento do pessoal envolvido & $\begin{array}{l}\text { Confiança e } \\
\text { conhecimento da } \\
\text { equipe }\end{array}$ \\
\hline At17 & Comprometimento no atendimento (resposta rápida ao cliente) & Agilidade na entrega \\
\hline At18 & Ações tomadas quando você teve reclamações & Recuperação de falhas \\
\hline At19 & $\begin{array}{l}\text { Comunicação clara da empresa com você sobre preços, } \\
\text { condições do contrato, etc. }\end{array}$ & Comunicação \\
\hline At20 & Compatibilidade do sistema de comunicação da empresa com o seu sistema & Comunicação \\
\hline At21 & Modernidade da frota de transporte & $\begin{array}{l}\text { Entrega sem danos ao } \\
\text { produto }\end{array}$ \\
\hline At22 & Segurança da carga transportada & $\begin{array}{l}\text { Entrega sem danos ao } \\
\text { produto }\end{array}$ \\
\hline Q23 & Satisfação geral com a Empresa Logística & - \\
\hline Q24 & Intenção de continuar trabalhando com a empresa logística (lealdade) & - \\
\hline
\end{tabular}

Fonte: dados de pesquisa.

exploratória com o método de extração de componentes principais e rotação Varimax com normalização Kaiser. A análise fatorial tem como objetivo, segundo Maroco (2003), quantificar construtos que não podem ser observados diretamente. A redução do número de variáveis é efetuada pelo agrupamento de variáveis altamente correlacionadas para formar um fator, o qual é composto pela combinação linear de variáveis (DILLON; GOLDSTEIN, 1984). As cargas fatoriais, assim como os coeficientes de correlação, sofrem uma variação de $-1,00$ a 1,00, sendo que, quanto mais próximo de 1,00 , maior a correlação existente entre o atributo e a dimensão. (PASQUALI, 2002).

O Tabela 4 mostra o resultado da análise fatorial para os dados da pesquisa, para as empresas que utilizam mais de um fornecedor logístico. A inclusão das empresas que operavam apenas com a empresa logística pesquisada causou muita instabilidade na análise, com atributos com cargas fatoriais expressivas em várias dimensões. As empresas que trabalham com mais de um operador logístico têm mais condições de avaliar a qualidade dos serviços prestados, sendo que a instabilidade na análise pode ser devida a uma diferença nas dimensões da qualidade do serviço entre os dois grupos. Assim, optou-se por eliminar da análise fatorial os casos das empresas que utilizam apenas a empresa logística pesquisada (31). Os casos em branco foram eliminados pelo método listwise do SPSS. A análise fatorial exploratória extraiu cinco fatores, ou dimensões, que explicam $71 \%$ da variância 
dos dados. O atributo At17 - Comprometimento no atendimento (resposta rápida ao cliente) - foi eliminado da análise devido ao grande número de casos em branco. As cargas fatoriais menores que 0,5 não foram mostradas no Tabela 4 .

A primeira dimensão agrupou os atributos que estão ligados com aspectos da rapidez do atendimento, tendo sido denominada de Responsividade. A segunda dimensão agrupou os atributos ligados à flexibilidade da empresa no atendimento ao cliente, tendo sido denominada Flexibilidade. A terceira dimensão agrupou os atributos relacionados com a garantia e tranquilidade que o cliente tem em operar com a empresa, tendo sido denominada de Segurança. A quarta dimensão agrupou os atributos relacionados com o desempenho do serviço, tendo sido denominada de Confiabilidade. A quinta dimensão relaciona-se com a capacidade da empresa em atender a requisitos especiais do cliente, denominada de Empatia. Assim, a pesquisa mostrou que, ao menos para os clientes da empresa logística pesquisada, a qualidade do serviço pode ser avaliada pelas 5 dimensões, sendo que quatro das dimensões se enquadram naquelas propostas por Parasuraman, Zeithaml e Berry (1988).

A Tabela 5 mostra o resultado da regressão linear entre as dimensões identificadas para a qualidade da empresa logística e a Satisfação Geral dos clientes.

A dimensão de maior peso foi Segurança, com grande distância para Confiabilidade, Responsividade e Empatia. Já a dimensão com menor impacto foi Flexibilidade. Pode-se verificar que a importância das dimensões para os clientes da empresa pesquisada difere daquelas encontradas por Berry e Parasuraman (1992), Landrum e Prybutok (2004) e Ling e Chong (2005), que indicam confiabilidade e responsividade como as dimensões mais importantes. Esta divergência pode ser devido a diferenças no contexto dos serviços (LADHARI, 2009), a diferença nas dimensões avaliadas ou pelo método de importância declarada para identificar o peso relativo dos atributos utilizado por esses autores. Os métodos de importância declarada e derivada tendem a dar resultados diferentes (GARVER, 2003; TONTINI; SILVEIRA, 2007), pois a importância atribuída é racional, já a importância derivada emerge dos dados, sem racionalidade por parte dos respondentes.

\section{Identificação de oportunidades de melhoria}

A Tabela 6 mostra os resultados da satisfação atual com os atributos, a importância declarada, e a correlação parcial (importância derivada) dos atributos com a satisfação geral dos clientes e com a intenção de continuar trabalhando com a empresa logística (lealdade).
Praticamente todos os atributos pesquisados influenciam a satisfação geral dos clientes e sua intenção de continuar trabalhando com a empresa (lealdade). Somente três atributos, At12 - Recuperação de Falhas, At4 - Não ter defeitos nas mercadorias transportadas e At5 - Capacidade de prestar serviços de urgência ou especiais não apresentam influência no nível de $95 \%$ de significância na lealdade.

A Figura 1 mostra a matriz de importância com a classificação dos atributos segundo o modelo Kano e a análise pela matriz de importância $\times$ desempenho. As linhas divisórias entre os quadrantes foram estabelecidas pela média das importâncias declarada e derivada e pela média da satisfação atual. Essas linhas são arbitrárias, cabendo ao time de projeto julgar a procedência das classificações, particularmente para os atributos próximos das linhas divisórias. Como regra prática, quando os atributos estão próximos às linhas divisórias, sugere-se que se proceda à classificação mais conservadora ou a que traria mais insatisfação aos clientes, caso o atributo fique com baixo desempenho.

Analisando-se a Figura 1a, os atributos At1, At2, At3, At4, At15, At6, At12 e At19 podem ser classificados como básicos. Já os atributos At22, At14, At17, At21, At18 e At11, podem ser considerados como chave para a satisfação dos clientes, ou seja, um alto desempenho trará satisfação e reconhecimento pelo cliente, já um baixo desempenho trará insatisfação. Os atributos At20, At13, At16 e At7 são considerados atrativos, podendo ser utilizados como diferenciais no mercado. Os atributos At5, At8, At9 e At10 são neutros.

Apenas classificar os atributos segundo o modelo Kano não é suficiente para que se possa tomar a decisão sobre qual atributo deveria ser melhorado, mantido ou poderia ser considerado um diferencial. Faz-se necessário averiguar a satisfação atual dos clientes com esses atributos e sua importância relativa. Assim, a Figura 1b mostra a matriz de importância e desempenho para os 22 atributos analisados. Novamente, as linhas divisórias foram estabelecidas na média da satisfação e do desempenho.

Conforme exposto anteriormente, devido ao efeito não linear dos atributos na satisfação geral, deve-se proceder à análise da matriz de importância e desempenho levando-se em consideração sua classificação pelo modelo Kano. A Tabela 7 mostra a comparação das classificações segundo o modelo Kano e pela matriz de importância e desempenho, para o caso da empresa logística em análise. Os diferenciais de uma empresa são dados pelos seus pontos fortes, no caso de atributos-chave ou atrativos. Já seus pontos fracos são dados pelos atributos básicos ou chave com menor desempenho.

No caso da empresa logística em análise, pode-se dizer que ela se distingue, aos olhos de seus clientes, 
Tabela 4. Dimensões da qualidade do serviço da empresa pesquisada.

\begin{tabular}{|c|c|c|c|c|c|}
\hline & \multicolumn{5}{|c|}{ Fatores } \\
\hline & 1 & 2 & 3 & 4 & 5 \\
\hline At15 - Rapidez no atendimento em contato c/ empresa & 0,75 & - & - & - & - \\
\hline At12 - Recuperação de falhas ocorridas no serviço & 0,68 & - & - & - & - \\
\hline At11 - Agilidade na entrega & 0,66 & - & - & - & - \\
\hline At4 - Não ter defeitos nas mercadorias transportadas & 0,64 & - & - & - & - \\
\hline At16 - Nível de conhecimento do pessoal envolvido & 0,54 & - & - & - & - \\
\hline At5 - Capacidade de prestar serviços de urgência ou especiais & - & 0,80 & - & - & - \\
\hline At6 - Flexibilidade nos prazos de entrega e coleta & - & 0,79 & - & - & - \\
\hline At8 - Frequência e periodicidade de coleta e entrega & - & 0,62 & - & - & - \\
\hline At9 - Aviso antecipado de atrasos & - & 0,61 & - & - & - \\
\hline At10 - Informações sobre status do pedido (rastreabilidade) & - & 0,55 & - & - & - \\
\hline $\begin{array}{l}\text { At7 - Política de devolução de mercadorias } \\
\text { enviadas erradas por fornecedores }\end{array}$ & - & 0,54 & - & - & - \\
\hline At21 - Modernidade da frota de transporte & - & - & 0,78 & - & - \\
\hline At20 - Compatibilidade do sistema de informação com o de sua empresa & - & - & 0,77 & - & - \\
\hline At22 - Segurança da carga transportada & - & - & 0,64 & - & - \\
\hline At18 - Ações tomadas quando há reclamações & - & - & 0,59 & - & - \\
\hline At19 - Comunicação sobre preços, condições de contrato, etc. & - & - & 0,54 & - & - \\
\hline At3 - Entrega completa & - & - & - & 0,82 & - \\
\hline At2 - Entrega de produto correto & 0,50 & - & - & 0,67 & - \\
\hline At1 - Pontualidade na entrega & - & - & - & 0,56 & - \\
\hline At14 - Cordialidade no atendimento & - & - & - & - & 0,80 \\
\hline $\begin{array}{l}\text { At13 - Flexibilidade no tipo de carga que pode } \\
\text { transportar (especiais ou perigosos) }\end{array}$ & - & - & - & - & 0,63 \\
\hline Variância total explicada (\%) & 18,00 & 35,00 & 52,00 & 62,00 & 71,00 \\
\hline Eigenvalues & 3,77 & 3,62 & 3,55 & 2,05 & 1,90 \\
\hline Alfa de Crombach & 0,84 & 0,85 & 0,85 & 0,77 & 0,77 \\
\hline $\begin{array}{l}\text { Método de extração: Análise de Componentes Principais } \\
\text { Método de Rotação: Varimax com Kaiser Normalization }\end{array}$ & - & - & - & - & - \\
\hline
\end{tabular}

Tabela 5. Regressão linear entre satisfação geral $\times$ dimensões da qualidade.

\begin{tabular}{|c|c|c|c|c|c|}
\hline & \multicolumn{2}{|c|}{ Coeficientes não padronizados } & \multirow{2}{*}{$\begin{array}{c}\text { Coeficientes padronizados } \\
\text { Beta }\end{array}$} & \multirow[t]{2}{*}{$\mathbf{t}$} & \multirow[t]{2}{*}{ Sig. } \\
\hline & & Erro padrão & & & \\
\hline Constante & 2,90 & 0,08 & & 37,93 & 0,000 \\
\hline Responsividade & 0,47 & 0,08 & 0,31 & 6,05 & 0,000 \\
\hline Flexibilidade & 0,32 & 0,08 & 0,21 & 4,06 & 0,000 \\
\hline Segurança & 0,80 & 0,08 & 0,51 & 10,07 & 0,000 \\
\hline Confiabilidade & 0,56 & 0,07 & 0,39 & 7,66 & 0,000 \\
\hline Empatia & 0,51 & 0,08 & 0,33 & 6,54 & 0,000 \\
\hline
\end{tabular}

$\mathrm{R}^{2}$ ajustado $=0,655$. Significância da Equação pela ANOVA $<0,001$.

pela cordialidade no atendimento do pessoal da linha de frente e pela segurança da carga transportada (At14 e At22). Podemos também considerar como pontos fortes a pontualidade na entrega e a entrega completa (At1 e At3). Porém, por estes serem considerados atributos básicos, eles não são ganhadores de pedido e, portanto, não são fatores de distinção da empresa aos olhos de seus clientes. Pode-se dizer que os pontos fracos da empresa logística são a agilidade na entrega (At11), o comprometimento no atendimento (At17), a recuperação de falhas eventualmente ocorridas (At12), as ações tomadas quando há reclamações (At18) e a modernidade da frota (At21).

Os atributos At13 - flexibilidade na carga que pode ser transportada, At20 - compatibilidade dos sistemas de comunicação com os dos clientes 

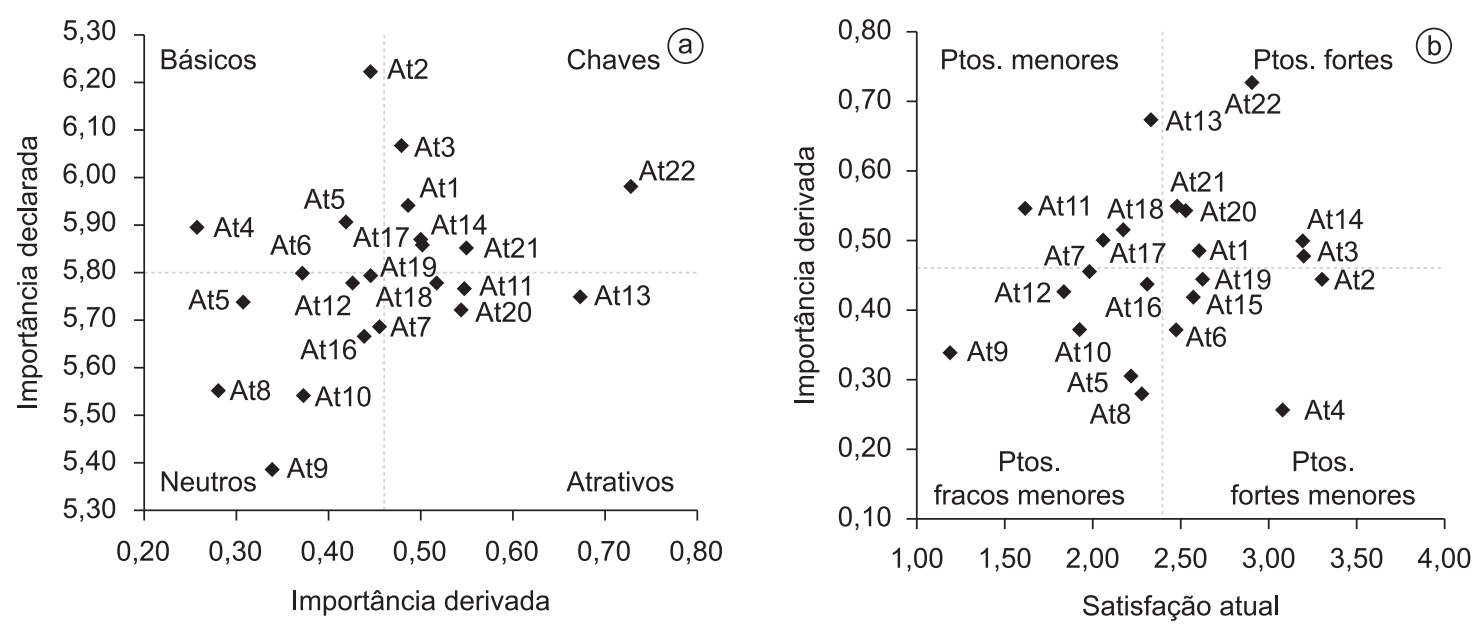

Figura 1. Classificação modelo Kano e matriz de importância $\times$ desempenho.

Tabela 6. Importância $\times$ satisfação atual para os atributos estudados.

\begin{tabular}{|c|c|c|c|c|c|}
\hline \multirow[t]{2}{*}{ Atributo } & \multicolumn{5}{|c|}{ Correlação com } \\
\hline & & $\begin{array}{l}\text { Sat. } \\
\text { geral }\end{array}$ & Lealdade & $\begin{array}{l}\text { Importância } \\
\text { declarada }\end{array}$ & $\begin{array}{l}\text { Satisfação } \\
\text { atual }\end{array}$ \\
\hline Pontualidade na entrega & At1 & 0,48 & 0,31 & 5,94 & 2,60 \\
\hline Entrega do produto correto & At2 & 0,44 & 0,29 & 6,23 & 3,30 \\
\hline Entrega completa & At3 & 0,48 & 0,28 & 6,07 & 3,20 \\
\hline Não ter defeitos nas mercadorias transportadas & At4 & 0,26 & $0,08 * *$ & 5,90 & 3,08 \\
\hline Capacidade de prestar serviços de urgência ou especiais & At5 & 0,31 & $0,13 *$ & 5,74 & 2,22 \\
\hline Flexibilidade nos prazos de entrega e coleta & At6 & 0,37 & 0,28 & 5,80 & 2,48 \\
\hline $\begin{array}{l}\text { Política de devolução de mercadorias enviadas erradas } \\
\text { pelos fornecedores }\end{array}$ & At7 & 0,46 & 0,28 & 5,69 & 1,98 \\
\hline Frequência e periodicidade de coleta e entrega & At8 & 0,28 & 0,31 & 5,55 & 2,28 \\
\hline Aviso antecipado de atrasos & At9 & 0,34 & 0,23 & 5,38 & 1,19 \\
\hline Informações sobre status do pedido (rastreabilidade) & At10 & 0,37 & 0,28 & 5,54 & 1,92 \\
\hline Agilidade na entrega (tempo entre coleta e entrega) & At11 & 0,55 & 0,32 & 5,77 & 1,61 \\
\hline Recuperação de falhas eventualmente ocorridas no serviço & At12 & 0,43 & $0,19 *$ & 5,78 & 1,84 \\
\hline $\begin{array}{l}\text { Flexibilidade no tipo de carga que pode transportar } \\
\text { (especiais ou perigosos) }\end{array}$ & At13 & 0,67 & 0,49 & 5,75 & 2,33 \\
\hline Cordialidade no atendimento & At14 & 0,50 & 0,43 & 5,87 & 3,19 \\
\hline $\begin{array}{l}\text { Rapidez no atendimento quando entra em contato com } \\
\text { a empresa }\end{array}$ & At15 & 0,42 & 0,40 & 5,91 & 2,57 \\
\hline Nível de conhecimento do pessoal envolvido & At16 & 0,44 & 0,25 & 5,66 & 2,31 \\
\hline $\begin{array}{l}\text { Comprometimento no atendimento (resposta rápida ao } \\
\text { cliente) }\end{array}$ & At17 & 0,50 & 0,41 & 5,86 & 2,06 \\
\hline Ações tomadas quando há reclamações & At18 & 0,52 & 0,46 & 5,78 & 2,17 \\
\hline Comunicação sobre preços e condições do contrato, etc. & At19 & 0,44 & 0,41 & 5,79 & 2,63 \\
\hline $\begin{array}{l}\text { Compatibilidade do sistema de comunicação da } \\
\text { empresa com seu sistema }\end{array}$ & At20 & 0,54 & 0,45 & 5,72 & 2,53 \\
\hline Modernidade da frota de transporte & At21 & 0,55 & 0,46 & 5,85 & 2,48 \\
\hline Segurança da carga transportada & At22 & 0,73 & 0,49 & 5,98 & 2,90 \\
\hline Média dos atributos & & 0,46 & 0,33 & 5,80 & 2,40 \\
\hline
\end{tabular}

Correlações parciais controladas pela frequência de utilização dos serviços da empresa e se utiliza serviço de outra empresa.

$* *$ p-value $>0,1 *$ p-value $>0,05$ (para lealdade). 
Tabela 7. Classificação dos atributos pelo modelo Kano $\times$ análise de importância $\times$ desempenho.

\begin{tabular}{|c|c|c|c|}
\hline Atributos & & $\begin{array}{l}\text { Classificação } \\
\text { modelo Kano }\end{array}$ & $\begin{array}{l}\text { Posição matriz } \\
\text { import. } \times \text { desemp. }\end{array}$ \\
\hline Pontualidade na entrega & At1 & Básico & Ponto forte \\
\hline Entrega do produto correto & At2 & Básico & Ponto forte menor \\
\hline Entrega completa & At3 & Básico & Ponto forte \\
\hline Não ter defeitos nas mercadorias transportadas & At4 & Básico & Ponto forte menor \\
\hline Capacidade de prestar serviços de urgência ou especiais & At5 & Neutro & Ponto fraco menor \\
\hline Flexibilidade nos prazos de entrega e coleta & At6 & Básico & Ponto forte menor \\
\hline $\begin{array}{l}\text { Política de devolução de mercadorias enviadas erradas pelos } \\
\text { fornecedores }\end{array}$ & At7 & Atrativo & Ponto fraco \\
\hline Frequência e periodicidade de coleta e entrega & At8 & Neutro & Ponto fraco menor \\
\hline Aviso antecipado de atrasos & At9 & Neutro & Ponto fraco menor \\
\hline Informações sobre status do pedido (rastreabilidade) & At10 & Neutro & Ponto fraco menor \\
\hline Agilidade na entrega (tempo entre coleta e entrega) & At11 & Chave & Ponto fraco \\
\hline Recuperação de falhas eventualmente ocorridas no serviço & At12 & Básico & Ponto fraco \\
\hline $\begin{array}{l}\text { Flexibilidade no tipo de carga que pode } \\
\text { transportar (especiais ou perigosos) }\end{array}$ & At13 & Atrativo & Ponto fraco \\
\hline Cordialidade no atendimento & At14 & Chave & Ponto forte \\
\hline Rapidez no atendimento quando entra em contato com a empresa & At15 & Básico & Ponto forte menor \\
\hline Nível de conhecimento do pessoal envolvido & At16 & Atrativo & Ponto forte menor \\
\hline Comprometimento no atendimento (resposta rápida ao cliente) & At17 & Chave & Ponto fraco \\
\hline Ações tomadas quando há reclamações & At18 & Chave & Ponto fraco \\
\hline Comunicação sobre preços e condições do contrato, etc. & At19 & Básico & Ponto forte menor \\
\hline $\begin{array}{l}\text { Compatibilidade do sistema de comunicação da } \\
\text { empresa com seu sistema }\end{array}$ & At 20 & Atrativo & Ponto fraco \\
\hline Modernidade da frota de transporte & At21 & Chave & Ponto fraco \\
\hline Segurança da carga transportada & At22 & Chave & Ponto forte \\
\hline
\end{tabular}

e At7 - política de devolução de mercadorias são considerados pontos fracos pelos clientes, mas classificados como atrativos. Neste caso, a empresa não está perdendo clientes pelo fato de estar com desempenho mais baixo, mas poderia estar se diferenciando, pois os atributos atrativos são considerados ganhadores de pedido. Caso a análise fosse efetuada apenas pela Matriz de Importância e Desempenho, como estes atributos são considerados pontos fracos, a empresa poderia ser impelida a investir em, por exemplo, compatibilização de seus sistemas de comunicação com os clientes, deixando talvez de investir em algum outro ponto crítico da empresa. Este resultado confirma um dos possíveis problemas do uso isolado da Matriz de Importância e Desempenho apontados por Hüiskonen e Pirtillä (1998), citados na Tabela 2.

Cruzando-se a importância dos atributos para a lealdade dos clientes (Tabela 6) com sua classificação pelo modelo Kano (Tabela 7), verificamos que entre os dez atributos de maior impacto na lealdade estão seis atributos-chave (At22, At18, At21, At14, At17, At11), dois atrativos (At13, At20) e dois básicos
(At5, At19). Entre os dez atributos de menor impacto na lealdade verificam-se cinco básicos (At2, At6, At3, At12 e At4), dois atrativos (At7, At16) e três neutros (At10, At9, At5). Verifica-se assim o grande impacto dos atributos-chave na lealdade. Verificando-se a Tabela 5, vemos que, entre os atributos de maior impacto na lealdade, a empresa logística está apresentando baixo desempenho em quase todos os atributos-chave, exceto no atributo de segurança da carga transportada (AT22) e cordialidade no atendimento das pessoas da linha de frente (At14), que foram considerados pontos fortes.

O diagnóstico geral para a empresa logística analisada é que ela tem se mantido no mercado devido a sua pontualidade de entrega e capacidade de entrega completa. Tem ganhado novos clientes devido à cordialidade das pessoas da linha de frente e à segurança da carga transportada, provavelmente pela existência de rastreamento via satélite em seus caminhões. Já, agilidade do atendimento e as ações tomadas em caso de falhas deveriam ser melhoradas urgentemente. 


\section{Conclusões}

A literatura da área sugere que a qualidade dos serviços logísticos pode ter até 13 dimensões. Porém, este estudo mostrou que a qualidade do serviço logístico para os clientes da empresa pesquisada concentra-se em cinco dimensões: Confiabilidade, Responsividade, Flexibilidade, Segurança e Empatia. Mais especificamente para o serviço logístico, essas dimensões podem ser traduzidas como: confiabilidade da entrega quanto a prazo e quantidade; agilidade na entrega e de resposta ao cliente; segurança em realizar negócios com a empresa; flexibilidade na prestação dos serviços; e capacidade de atender a necessidades especiais.

Quanto à influência dos diversos atributos na satisfação e na lealdade dos clientes, verificou-se que a lealdade é mais influenciada pelos atributos classificados como "chave" pelo modelo Kano (At22 - Segurança da Carga Transportada, At18 Ações Tomadas pela empresa na ocorrência de reclamações, At21 - Modernidade da Frota de Transporte, At14 - Cordialidade do pessoal da linha de frente, At17 - Comprometimento no atendimento, At11 - Agilidade na entrega).

O estudo confirmou também a existência dos erros apontados por Huiskonen e Pirtillä (1998) quando se utiliza a matriz de importância e desempenho para identificação das oportunidades de melhoria, sem a avaliação da relação não linear entre desempenho dos atributos e a satisfação geral. Este foi o caso para os atributos At13 - Flexibilidade na carga que pode ser transportada, At20 - Compatibilidade dos sistemas de comunicação com os dos clientes e At7 - Política de devolução de mercadorias, que são considerados pontos fracos pelos clientes, mas classificados como atrativos pelo modelo Kano. Caso a análise fosse efetuada apenas pela Matriz de Importância e Desempenho, como estes atributos são considerados pontos fracos, a empresa poderia ser impelida a investir em sua melhoria, deixando talvez de investir em algum outro ponto crítico da empresa.

Quanto à empresa logística analisada, conclui-se que deve estar se mantendo no mercado devido a sua pontualidade de entrega e capacidade de entrega completa. Tem ganhado novos clientes devido à cordialidade das pessoas da linha de frente e à segurança da carga transportada. Já, agilidade do atendimento e as ações tomadas em caso de falhas deveriam ser melhoradas urgentemente.

Como recomendações gerenciais, este estudo mostra a importância de se levar em consideração a relação não linear entre o desempenho dos atributos individuais e a satisfação dos clientes, sob pena de se tomar decisões de melhoria equivocadas.

\section{Referências}

ANDERSON, E. W.; MITTAL, V. Strengthening the satisfaction-profit chain. Journal of Service Research, v. 3, n. 2, p. 107-120, 2000.

BALLOU, R. H. Logística empresarial. São Paulo: Atlas, 1995.

BALLOU, R. H. Gerenciamento da cadeia de suprimentos: planejamento, organização e logística empresarial. 4. ed. São Paulo: Bookman, 2001.

BERGER, C. et al. Kano's methods for understanding customer-defined quality. Journal of the Japanese Society for Quality Control, v. 23, n. 2, p. 3-35, 1993.

BERRY, L. L.; PARASURAMAN, A. Serviços de marketing: competindo através da qualidade. São Paulo: Maltese-Norma, 1992. 238 p.

BIENSTOCK, C. C. et al. An expanded model of logistics service quality: Incorporating logistics information technology. International Journal of Production Economics, n. 113, p. 205-222, 2008.

BIENSTOCK, C. C.; MENTZER, J. T.; BIRD; M. M. Measuring physical distribution service quality. Journal of the Academy of Marketing Science, v. 25, n. 1, p. 31-44, 1997.

BOWERSOX, D. J.; CLOSS, D. J. Logistical management - the integrated supply chain process. Michigan: McGraw-Hill, 1996.

BOWERSOX, D. J.; CLOSS, D. J. Logística empresarial. São Paulo: Atlas, 2001.

BRANDT, R. D. How service marketers can identify value-enhancing service elements. The Journal of Services Marketing, v. 2, n. 3, p. 35-41, 1988.

CENTRO DE ESTUDOS EM LOGÍSTICA - CEL. Pesquisa de benchmark - serviço ao cliente. 2003. Disponível em: <www.cel.coppead.ufrj.br>. Acesso em: 26 fev. 2004.

CHOWDHARY, N.; PRAKASH, M. Prioritizing service quality dimensions. Managing Service Quality, v. 17, n. 5, p. 493-509, 2007.

CHRISTOPHER, M. Logística e gerenciamento da cadeia de suprimentos. São Paulo: Pioneira, 1997.

DILLON, W. R.; GOLDSTEIN, M. Multivariate analysis. New York: John Wiley \& Sons, 1984.

ELLRAM L. M.; LA LONDE, B. J., WEBER, M. M. Retail logistics. International Journal of Physical Distribution and Logistics Management, v. 29, n. 7/8, 1999.

EMERSON, C. J.; GRIMM, C. M. The relative importance of logistics and marketing - customer service: a strategic perspective. Journal of Business Logistics, v. 19, n. 1, 1998.

EMERY, C. R.; TIAN, R. G. Schoolwork as products, professors as customers: a practical teaching approach in business education. Journal of Education for Business, v. 78, n. 2, p. 97-102, 2002.

FLEURY, P. F.; SILVA, C. R. L. Avaliação do serviço de distribuição física: relação entre a industria de bens de consumo e o comércio atacadista e varejista. In: FLEURY, P. F., WANKE, P.; FIGUEIREDO, K. F. Logística empresarial: a perspectiva brasileira. São Paulo: Atlas 2000. p. 76-92. 
FORSLUND, H. Assessing Customers' logistics quality gaps in the order fulfillment process. In: EUROMA AND POMS JOINT INTERNATIONAL CONFERENCE, 1 ., 2003, Italy. Proceedings...

GARVER, M. S. Best practices in identifying customerdriven improvement opportunities. Industrial Marketing Management, New York, v. 32, p. 455-466, 2003.

GEFEN, D. Customer loyalty in e-commerce. Journal of the Association for Information Systems, v. 3, p. 27-51, 2002.

GITLOW, H. S. Planejando a qualidade, a produtividade e a competitividade. Rio de Janeiro: Qualitymark, 1993.

GONÇALVES FILHO, C. et al. Mensurando a qualidade de serviços logísticos e intenções comportamentais de varejistas: um estudo empírico na indústria de refrigerantes. In: ENCONTRO DA ANPAD, 31., 2007. Anais... p. 16.

GRÖNROOS, C. Marketing: gerenciamento de serviços: a competição por serviços na hora da verdade. Rio de Janeiro: Campus, 1995.

GUSTAFSSON, A. Retail requirements on logistic service. In: EUROMA AND POMS JOINT INTERNATIONAL CONFERENCE, 2003. Proceedings...

GUSTAFSSON, A.; JOHNSON, M. D. Determining attribute importance in a service satisfaction model. Journal of Service Research, v. 7, n. 2, p. 124-141, 2004.

HARDING, F. E. Logistics service provider quality: private measurement, evaluation, and improvement. Journal of Business Logistics, v. 19, n. 1, p. 103-120, 1998.

HARRINGTON, T. C.; LAMBERT, D. M. E.; CHRISTOPHER, M. A Methodology for measuring vendor performance. Journal of Business Logistics, v. 12 p. 83-104, 1991.

HESKETT, J. Controlling customer logistics service. International Journal of Physical Distribution, v. 1, n. 3, p. 140-145, 1971.

HOLCOMB, M. C. Customer service measurement: a methodology for increasing customer value through utilization of the taguchi strategy. Journal of Business Logistics, v. 15 p. 29-52, 1994.

HUISKONEN, J.; PIRTTILÄ, T. Sharpening logistics customer service strategy planning by applying Kano's quality element classification. International Journal of Production Economics, n. 56-57, p. 253-260, 1998.

JACOBS, R. How to Conduct a Kano Model Analysis. European Media Management Review, v. 2, n. 1, 1999.

$\mathrm{KANO}$, N. et al. Attractive quality vs must be quality. Journal of the Japanese Society for Quality Control, v. 14, n. 2, p. 39-48, 1984.

KANO, N., Life cycle and creation of attractive quality, Proceedings of the 4th QMOD Conference, Linköping, Suécia, 2001.

KOTLER, P. Administração de marketing: a edição do novo milênio. 10. ed. São Paulo: Prentice Hall, 2000.

LADHARI, R. A review of twenty years of SERVQUAL research. International Journal of Quality and Services Sciences, v. 1, n. 2, p. 172-198, 2009.

LADHARI, R. Developing e-service quality scales: a literature review. Journal of Retailing and Consumer Services, 2010. doi:10.1016/j.jretconser.2010.06.003.
LAMBERT, D . M.; HARRINGTON, T. C. Establishing Customer Service Strategies Within the Marketing Mix: More Empirical Evidence. Journal of Business Logistics, v. 10, n. 2, p. 44-60, 1989.

LANDRUM, H.; PRYBUTOK, V. R. A service quality and success model for the information service industry. European Journal of Operational Research, n. 156, p. 628-642, 2004.

LING, F. Y. Y.; CHONG, C. L. K. Design-and-build contractors' service quality in public projects in Singapore. Building and Environment, n. 40, p. 815-823, 2005.

LU, C. S. Logistics services in taiwanese maritime firms. Transportation Research, v. 36, Part. E, p. 79-96, 2000. MAROCO, J. Análise estatística. 2. ed. Lisboa: Edições Silabo, 2003.

MARTENSEN, A.; GRÖNHOLDT, L. Using employee satisfaction measurement to improve people management: an adoption of Kano's quality types. Total Quality Management, v. 12, n. 7-8, p. 949-957, 2001.

MARTILLA, J. A.; JAMES, J. C. Importance-performance analysis. Journal of Marketing, n. 9, p. 41-77, 1977.

MARTÍNEZ CARO, L.; MARTÍNEZ GARCIA, J. A. Measuring perceived service quality in urgent transport service. Journal of Retailing and Consumer Services, v. 14, p 60-72, 2007.

MATZLER, K. et al. How to delight your customers. Journal of Product \& Brand Management, vol. 2, p. 6-17, 1996.

MATZLER, K.; SAUERWEIN, E. The factor structure of customer satisfaction: an empirical test of the importance grid and penalty-reward-contrast analysis. International Journal of Service Industry Management, v. 13, n. 4, p. 314-332, 2002.

MENTZER, J. T., FLINT, D. J., KENT, J. T. Developing a logistics service quality scale. Journal of Business Logistics, v. 20, n. 1, p. 9-32, 1999.

MITTAL, V.; ROSS, W. T. R.; BALDASARE, P. M. The asymmetric impact of negative and positive attribute-level performance on overall satisfaction and repurchase intentions. Journal of Marketing, v. 62, n. 1, p. 33-47, 1988.

MORAES, M. N.; LACOMBE, A. Medição de qualidade em serviços de distribuição: um estudo de caso. In: ENANPAD, 23., 1999, Foz do Iguaçu. Anais...

NILSON-WITELL, L.; FUNDIN, A. Dynamics of service attributes: a test of Kano's theory of attractive quality. International Journal of Service Industry Management, v. 16, n. 2, p. 152-168, 2005.

PARASURAMAN, A.; ZEITHAML, V. A.; BERRY, L. L. A conceptual model of service quality and its implications for future research. Journal of Marketing, v. 49, n. 4, p. 41-50, 1985.

PARASURAMAN, A.; ZEITHAML, V. A.; BERRY, L. L. Servqual: a multiple-item scale for measuring consumer perceptions of service quality. Journal of Retailing, v. 64, n. 1, p. 12-40, 1988.

PASQUALI, L. Análise fatorial para pesquisadores. Brasília: UnB, 2002. 
PICOLO, J. D.; TONTINI, G. Penalty and Reward Contrast Analysis (PRC): Identifying Improvement Opportunities in a Service. Revista de Administração Makenzie, v. 9, n. 5, p. 35-58, 2008.

SHARMA, A.; GREWAL, D.; LEVY, M. The Breakthrough Thinking in Logistics. Journal of Business Logistics, v. 16, n. 2, 1995.

SLACK, N. et al. Administração da produção. São Paulo: Atlas, 2000.

SEBRAE-SC. Serviço de Apoio as Micro e Pequenas Empresas de Santa Catarina, Serviço de Estatísticas sobre MPE's. Disponível em: <http://www.sebrae-sc. com.br>. Acesso em: 19 de Maio 2010.

SOUZA, M. F. S.; MOORI, R. G.; MARCONDES R. C. Sincronização das Expectativas dos Clientes com a Prática dos Fornecedores Quanto a Custos, Confiabilidade e Qualidade. In: ENANPAD, 27., 2003, Atibaia. Anais...
TONTINI, G.; SANT'ANA, A. J. identificação de atributos críticos de satisfação em um serviço através da análise competitiva do gap de melhoria. Gestão e Produção, v. 14, n. 1, p. 43-54, 2007.

TONTINI, G.; SILVEIRA, A. Identification of satisfaction attributes using competitive analysis of the improvement gap. International Journal of Operations \& Production Management, v. 27, n. 5, p. 482-500, 2007. DOI 10.1108/01443570710742375.

WITELL, L.; LÖFGREN, M. Classification of quality attributes. Managing Service Quality, v. 17, n. 1, p. 54-73, 2007.

ZEITHAML, V. A.; BITNER, M. J. Marketing de serviços: a empresa com foco no cliente. 2. ed. Porto Alegre : Bookman, 2003. 536 p. Tradução de: Services marketing - integrating customer focus across the firm. 